\title{
Avaliação de sistemas de classificação climática para a vertente paranaense da bacia hidrográfica do rio Itararé
}

\section{Evaluation of climate classification systems of the Parana state slope of the Itararé watershed}

\author{
Paulo Miguel de Bodas Terassi \\ Doutorando em Geografia Física pela Universidade de São Paulo - Bolsista CAPES, Brasil \\ pmbterassi@usp.br
}

José Tadeu Garcia Tommaselli

Professor Doutor do Departamento de Geografia e do Programa de Pós-Graduação em Geografia da Universidade Estadual Paulista "Júlio de Mesquita Filho" - Campus de Presidente Prudente, Brasil

$\underline{\text { tadeu@fct.unesp.br }}$

\section{Resumo}

Este trabalho tem como objetivo avaliar três diferentes tipologias climáticas que apresentam diferentes formas de identificação das características climáticas da vertente paranaense da bacia hidrográfica do rio Itararé. Foram obtidos os dados de treze postos pluviométricos junto ao Instituto das Águas do Paraná e de uma estação meteorológica, de Joaquim Távora, pertencente ao Instituto Agronômico do Paraná, para a série histórica de 1976 a 2012. Foram utilizadas as estimativas de temperatura fornecidas pela Universidade de Delaware (2014). Foram aplicados os sistemas de classificação climática de Köppen (1948), Thornthwaite (1948) e Nimer (1972). Empregou-se a técnica de agrupamento para a escolha de anos excepcionais. O emprego do sistema de classificação climática de Köppen (1948) possibilitou delimitar a área de estudo em três tipologias climáticas: $\mathrm{Cfb}$ para os setores oeste e central; $\mathrm{Cfa}$ para o setor norte; $\mathrm{Cfa} / \mathrm{Cfb}$ para os setores transitórios. A metodologia de Thornthwaite (1948) apresentou seis tipologias climáticas distinguindo apropriadamente as características climáticas da bacia hidrográfica em conformidade com o índice de umidade efetiva e a eficiência térmica. A metodologia de Nimer (1972) identificou três tipologias climáticas e definiu características da circulação atmosférica a partir dos atributos climáticos. A aplicação dos sistemas de classificação climática para os anos excepcionais mostrou que o ano de 1985 apresentou tipologias climáticas do clima semi-árido, ao passo que, para o ano de 1983, o método de Thornthwaite (1948) não descreveu a ocorrência de meses secos verificadas pela classificação climática de Nimer (1972).

Palavras-chave: classificação climática, bacia hidrográfica, anos anômalos.

\begin{abstract}
This paper aims to evaluate three different climate types, which have different ways of identifying the climatic characteristics of Paraná state slope of Itararé watershed. Were obtained rainfall data of thirteen rain gauge stations along with the Paraná Institute of Water and the weather station Joaquim Távora, which belongs to the Agronomic Institute of Paraná, for the historical data serie to 1976-2012. Were apllied the climatic classification systems of Koppen (1948), Thornthwaite (1948) and Nimer (1972). Was employed the clustering technique to define exceptional years. The usage of Köppen's classification system (1948) allowed us to define the study area into three climatic types: $\mathrm{Cfb}$ for the western and central sectors; Cfa for the northern sector; $\mathrm{Cfa} / \mathrm{Cfb}$ for transient sectors. The methodology presented by Thornthwaite (1948) exposed six climate types, properly distinguishing the climatic characteristics of the watershed in accordance with the effective moisture and thermal efficiency. Nimer's methodology (1972) identified three climate types and defined the atmospheric circulation features through the climatic attributes. The application of climatic classification systems for exceptional years showed that the year 1985 presented climate
\end{abstract}


types of semi-arid climate, whereas for the rainy year of 1983 the Thornthwaite method (1948) not described the occurrence of dry months verified by climatic classification Nimer (1972).

Keywords: climate classification, watershed, anomalous years.

\section{INTRODUÇÃO}

As classificações climáticas têm importância na análise e definição climática levando em consideração diferentes elementos climáticos simultaneamente, facilitando a troca de informações para diferentes propósitos (ROLIM et al., 2007). Nóbrega (2010) descreve que os sistemas de classificação climática pautam-se de diferentes critérios, como a precipitação, a temperatura, a evapotranspiração potencial, a deficiência e/ou o excedente hídrico, a vegetação e as massas de ar, selecionados conforme as exigências.

O sistema de classificação climática elaborado por Wilhelm Köppen é o método classificatório mais utilizado por suas delimitações abrangentes e pela aplicação em todos os setores interessados em Climatologia. Esse método tem seus critérios de agrupamento que compreendem um conjunto de letras maiúsculas e minúsculas, cada uma com o objetivo de classificar as características espaciais e sazonais (MENDONÇA; DANNI-OLIVEIRA, 2007; PELL; FINLAYSON; MCMAHON, 2007).

Devido à utilização dos dados de evapotranspiração potencial, excedente ou deficiência hídrica, obtidos pelo balanço hídrico, mesmo com a manutenção do caráter analítico, Tubelis e Nascimento (1984) esclarecem que Thornthwaite (1948) inovou ao racionalizar a classificação climática, sendo considerado um avanço por considerar que um clima é seco ou úmido conforme a necessidade hídrica.

Destacam-se os métodos classificatórios baseados nos princípios da climatologia dinâmica, na qual a circulação e a dinâmica atmosférica constituem a base genética dos climas, pois têm na origem dos fenômenos climáticos como fundamento do sistema classificatório. Segundo Vianello e Alves (2004), esses métodos são denominados de genéticos por serem fundamentados nas configurações da circulação geral da atmosfera, além de fatores como a latitude, a altitude, a maritimidade e a continentalidade.

Este trabalho tem como objetivo avaliar três diferentes tipologias climáticas que apresentam diferentes formas de identificação das características climáticas da vertente paranaense da bacia hidrográfica do rio Itararé. Além disso, foram eleitos dois anos excepcionais com o intuito de investigar as características climáticas para além das normais climatológicas. 


\section{MATERIAIS E MÉTODOS}

A porção paranaense da bacia hidrográfica do rio Itararé está situada entre os Primeiro, Segundo e Terceiro Planaltos Paranaenses (MAACK, 2012), entre as coordenadas UTM 625000 e 675000 Em e 7420000 e 7300000 Nm, especificamente na zona 22S. A área da bacia abrange uma superfície aproximada de $4845 \mathrm{~km}^{2}$ (ITCG, 2014) e localiza-se nos setores nordeste e leste do estado do Paraná (Figura 1).

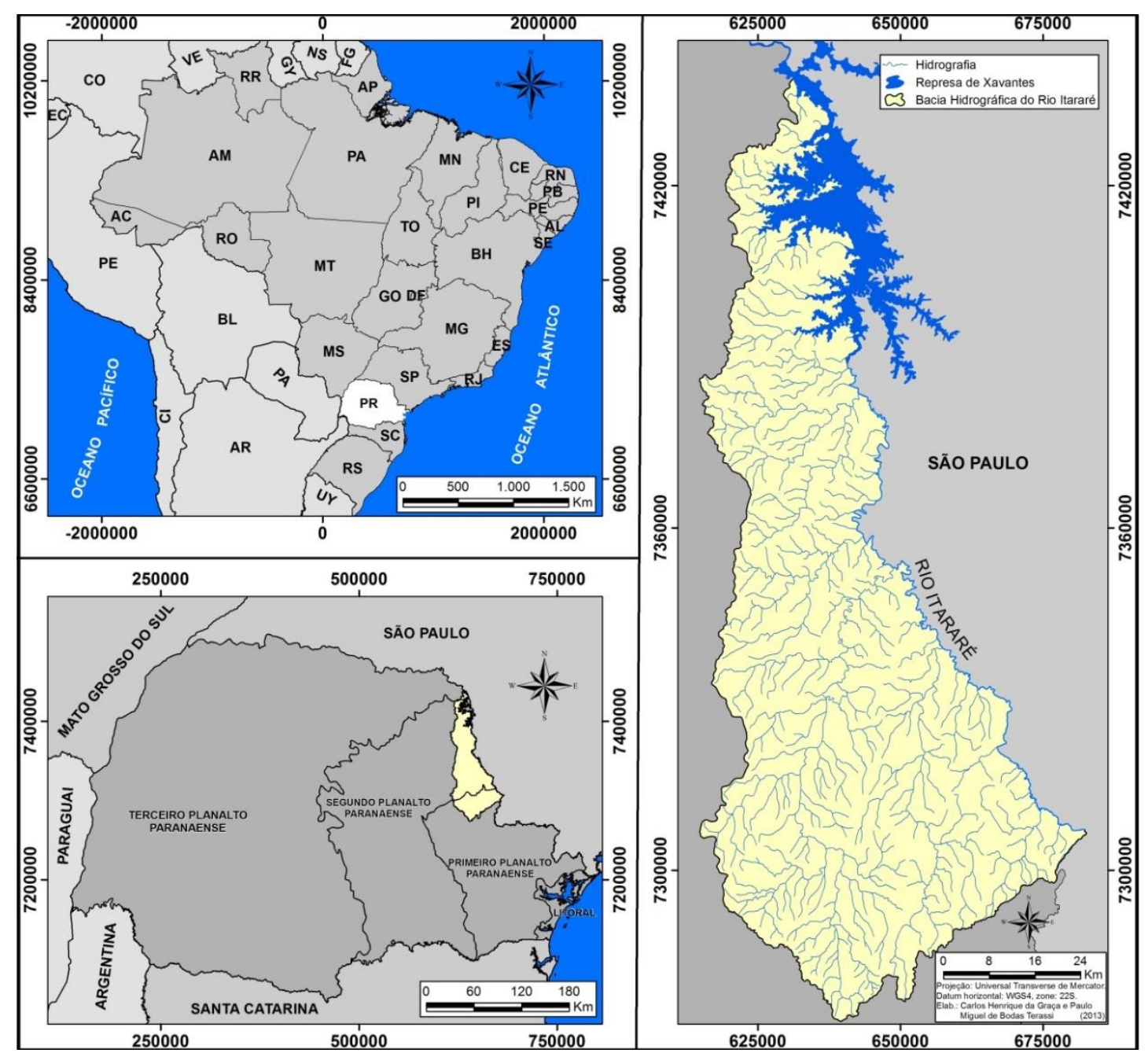

Figura 1 - Localização da vertente paranaense da bacia hidrográfica do rio Itararé.

Foram obtidos os dados de treze postos pluviométricos junto ao Instituto das Águas do Paraná e de uma estação meteorológica da rede do IAPAR (Instituto Agronômico do Paraná), em Joaquim Távora, trabalhados com segmento temporal de 1976 a 2012 (Quadro 1 - Figura 2). Os dados faltantes dos postos pluviométricos e estações meteorológicas foram preenchidos seguindo o método de ponderação regional apresentado por Villela e Mattos (1975), método que tem como base o registro pluviométrico de três postos localizados o mais próximo possível do posto em que se 
verifica a falta de dados, com características pluviométricas (distribuição mensal) e altitudes semelhantes.

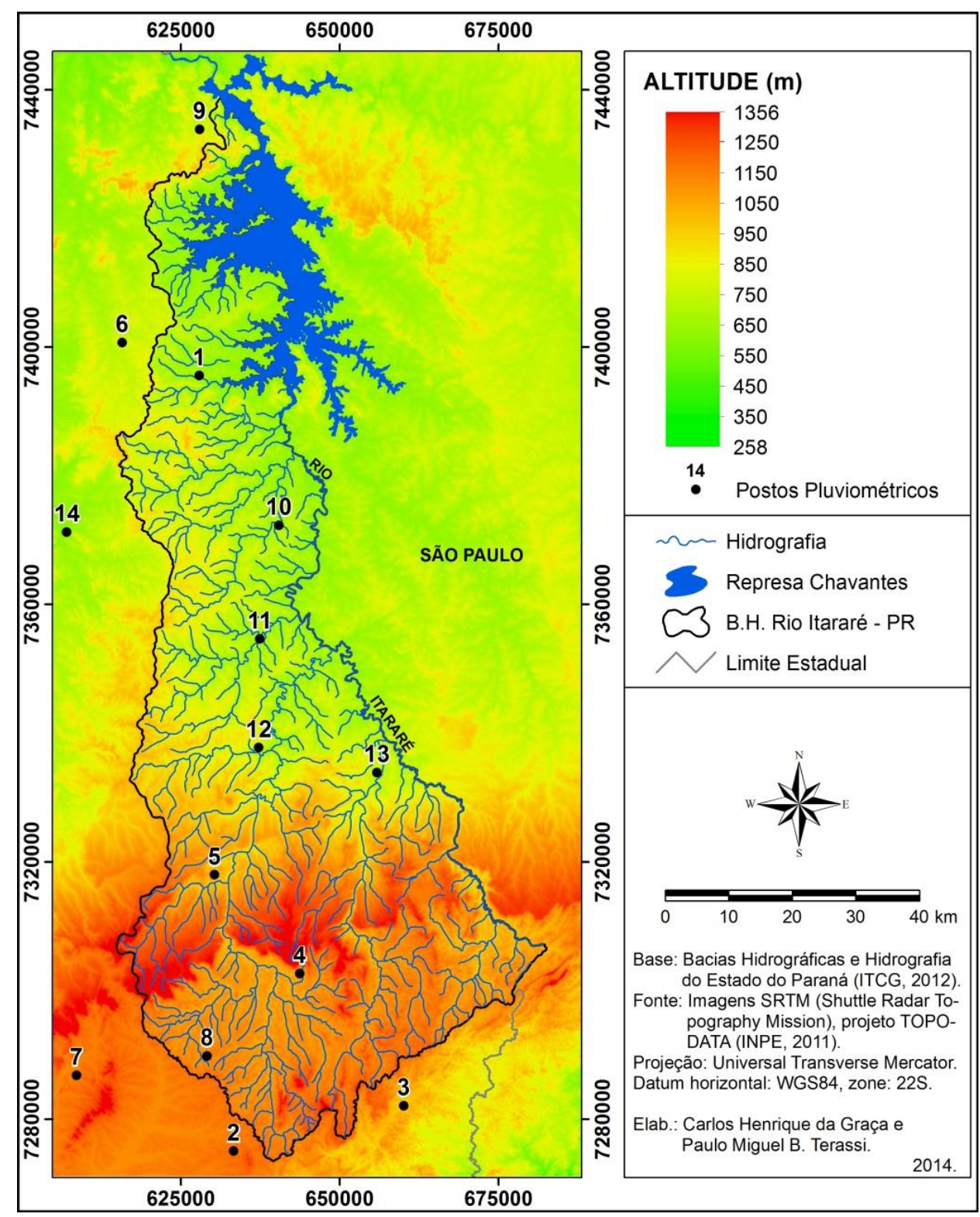

Figura 2 - Localização geográfica e hipsometria da estação meteorológica e dos postos pluviométricos para a vertente paranaense da bacia hidrográfica do rio Itararé - PR.

Os dados de temperatura foram obtidos das Estações Climatológicas de Joaquim Távora. Para as demais áreas da bacia hidrográfica foram atribuídos os valores de temperatura fornecidos pela Universidade de Delaware, sendo que se utilizaram os dados referentes ao segmento temporal de 1976 a 2010 (UDEL, 2014). Devido à inexistência dos dados de temperatura para os anos de 2011 e 2012, foram realizadas estimativas de temperatura média através do método de Ometto (1981), que considera uma variação de $0,65^{\circ} \mathrm{C}$ a cada 100 metros de altitude, tendo como base os dados da estação meteorológica de Joaquim Távora para os postos pluviométricos setentrionais e de 
Castro, também pertencente ao Instituto Agronômico do Paraná, para os postos pluviométricos meridionais.

Quadro 1 - Localização geográfica das dos postos pluviométricos e estação Meteorológica* na vertente paranaense da bacia hidrográfica do rio Itararé.

\begin{tabular}{|c|c|c|c|c|c|}
\hline $\begin{array}{c}\text { Número no } \\
\text { mapa de } \\
\text { localização }\end{array}$ & $\begin{array}{c}\text { Código da } \\
\text { ANEEL }\end{array}$ & $\begin{array}{c}\text { Posto Pluviométrico/ Estação } \\
\text { Meteorológica }\end{array}$ & $\begin{array}{c}\text { Latitude } \\
(\mathbf{S})\end{array}$ & $\begin{array}{c}\text { Longitude } \\
(\mathbf{W})\end{array}$ & $\begin{array}{c}\text { Altitude } \\
(\mathbf{m})\end{array}$ \\
\hline 1 & 02349060 & Carlópolis (Nova Brasília) & 7395526 & 627900 & 563 \\
\hline 2 & 02449030 & Castro (Fazenda Marão) & 7275043 & 633292 & 1100 \\
\hline 3 & 02449021 & Doutor Ulysses (Varzeão) & 7282084 & 660061 & 818 \\
\hline 4 & 02449036 & Jaguariaíva (Eduardo Xavier da Silva) & 7302629 & 643698 & 1000 \\
\hline 5 & 02449040 & Jaguariaíva & 7317956 & 630287 & 890 \\
\hline 6 & 02349030 & Joaquim Távora* & 7400672 & 615718 & 512 \\
\hline 7 & 02449011 & Piraí do Sul & 7286806 & 608541 & 1068 \\
\hline 8 & 02449032 & Piraí do Sul (Capinzal) & 7289831 & 629085 & 1026 \\
\hline 9 & 02349036 & Ribeirão Claro & 7433790 & 627919 & 782 \\
\hline 10 & 02349061 & Santana do Itararé & 7372279 & 640380 & 543 \\
\hline 11 & 02349064 & São José da Boa Vista & 7354589 & 637409 & 550 \\
\hline 12 & 02449045 & São José da Boa Vista (Barra Mansa) & 7337733 & 637247 & 850 \\
\hline 13 & 02449044 & Sengés & 7333850 & 655848 & 650 \\
\hline 14 & 02349033 & Tomazina & 7371211 & 606992 & 483 \\
\hline
\end{tabular}

Foram utilizadas as tipologias climáticas de Köppen (1948), Thornthwaite (1948) e Nimer (1972).

O sistema classificatório de Köppen (1948) é composto por três chaves que variam em conformidade com a temperatura média anual, temperatura do mês mais frio e do mês mais quente, pluviosidade média anual, máxima de verão e inverno, e o mês de maior ou menor precipitação. A tipologia climática de Köppen (1948) é descriminada a partir da definição do grupo - primeira letra maiúscula (Quadro 2), indicador de tipo - segunda letra minúscula (Quadro 3), e o indicador de subtipo - terceira letra minúscula (Quadro 4).

Quadro 2 - Caracterização do indicador de grupo climático (primeira chave) da Classificação Climática de Köppen (1948).

\begin{tabular}{|c|c|c|}
\hline Código & Tipo de Clima & Descriçãa \\
\hline A & Tropical & $\begin{array}{l}\text { Climas megatérmicos; temperatura média do mês mais frio superior a } 18{ }^{\circ} \mathrm{C} \text {; estação } \\
\text { invernosa ausente; pluviosidade anual superior a evapotranspiração potencial anual. }\end{array}$ \\
\hline B & Árido & $\begin{array}{l}\text { Climas secos; pluviosidade média anual inferior a } 500 \mathrm{~mm} \text {; evapotranspiração } \\
\text { potencial anual superior à pluviosidade anual; inexistência de cursos d'água } \\
\text { permanente. }\end{array}$ \\
\hline $\mathrm{C}$ & $\begin{array}{l}\text { Temperado - } \\
\text { Subtropical }\end{array}$ & $\begin{array}{l}\text { Climas mesotérmicos; temperatura média do mês mais frio entre }-3 \text { e } 18{ }^{\circ} \mathrm{C} \text {; } \\
\text { temperatura média do mês mais quente superior a } 10{ }^{\circ} \mathrm{C} \text {; Verão e inverno bem } \\
\text { definidos. }\end{array}$ \\
\hline $\mathrm{D}$ & Continental & $\begin{array}{l}\text { Climas microtérmicos; temperatura média do mês mais frio inferior a }-3{ }^{\circ} \mathrm{C} \text {; } \\
\text { temperatura média do mês mais quente superior a } 10^{\circ} \mathrm{C} \text {; Verão e inverno bem } \\
\text { definidos. }\end{array}$ \\
\hline $\mathrm{E}$ & Glacial & $\begin{array}{l}\text { Climas polares e de alta montanha; temperatura média do mês mais quente inferior a } \\
10^{\circ} \mathrm{C} \text {; Verão pouco definido ou inexistente. }\end{array}$ \\
\hline
\end{tabular}

Fonte: Köppen (1948). 
Quadro 3 - Caracterização do indicador do tipo climático (segunda chave) da Classificação Climática de Köppen (1948).

\begin{tabular}{|c|c|c|}
\hline Código & Descrição & Grupo \\
\hline $\mathrm{S}$ & $\begin{array}{l}\text { Clima das estepes; pluviosidade média anual entre } 360 \text { a } 760 \\
\text { mm. }\end{array}$ & $\mathrm{B}$ \\
\hline $\mathrm{W}$ & Clima desértico; pluviosidade média anual inferior a $250 \mathrm{~mm}$. & $\mathrm{B}$ \\
\hline $\mathrm{f}$ & $\begin{array}{l}\text { Clima úmido; ocorrência de pluviosidade em todos os meses } \\
\text { do ano; inexistência de estação seca definida; pluviosidade } \\
\text { média do mês mais seco superior a } 60 \mathrm{~mm} \text {. }\end{array}$ & A-C-D \\
\hline $\mathrm{W}$ & Chuvas de verão. & A-C-D \\
\hline $\mathrm{s}$ & Chuvas de inverno. & A-C-D \\
\hline W' & Chuvas de verão-outono. & A-C-D \\
\hline s' & Chuvas de outono-inverno. & A-C-D \\
\hline $\mathrm{m}$ & $\begin{array}{l}\text { Clima de monção; pluviosidade média anual superior a } 1500 \\
\text { mm e pluviosidade média mensal do mês mais seco inferior a } \\
60 \mathrm{~mm} \text {. }\end{array}$ & A-C-D \\
\hline $\mathrm{T}$ & Temperatura média do mês mais quente entre 0 a $10^{\circ} \mathrm{C}$ & A \\
\hline $\mathrm{F}$ & Temperatura média do mês mais quente inferior a $0{ }^{\circ} \mathrm{C}$. & $\mathrm{E}$ \\
\hline M & Precipitação abundante (inverno pouco rigoroso). & $\mathrm{E}$ \\
\hline
\end{tabular}

Fonte: Köppen (1948).

Quadro 4 - Caracterização do indicador de subtipo climático (terceira chave) da Classificação Climática de Köppen (1948).

\begin{tabular}{|c|l|c|}
\hline Código & \multicolumn{1}{|c|}{ Descrição } & Grupo \\
\hline $\mathrm{a}$ & $\begin{array}{l}\text { Verão quente; temperatura média do mês mais quente superior } \\
\mathrm{a} 22^{\circ} \mathrm{C} .\end{array}$ & C-D \\
\hline $\mathrm{b}$ & $\begin{array}{l}\text { Verão temperado; temperatura do mês mais quente inferior a } \\
22{ }^{\circ} \mathrm{C} ; \text { temperatura média dos quatro meses mais quentes } \\
\text { superior a } 10^{\circ} \mathrm{C} .\end{array}$ & C-D \\
\hline $\mathrm{c}$ & $\begin{array}{l}\text { Verão curto e fresco; temperatura média do mês mais quente } \\
\text { inferior a } 22^{\circ} \mathrm{C} ; \text { temperatura média inferior a } 10^{\circ} \mathrm{C} \text { durante } \\
\text { menos de quatro meses; temperatura média no mês mais frio } \\
\text { superior a }-38^{\circ} \mathrm{C} .\end{array}$ & C-D \\
\hline $\mathrm{d}$ & $\begin{array}{l}\text { Inverno muito frio; temperatura média do mês mais frio } \\
\text { inferior a }-38^{\circ} \mathrm{C} \text {. }\end{array}$ & $\mathrm{D}$ \\
\hline $\mathrm{h}$ & $\begin{array}{l}\text { Seco e quente; temperatura média do ar superior a } 18{ }^{\circ} \mathrm{C} ; \\
\text { deserto ou semideserto quente. }\end{array}$ & $\mathrm{B}$ \\
\hline $\mathrm{k}$ & $\begin{array}{l}\text { Seco e frio; temperatura média do ar inferior a } 18^{\circ} \mathrm{C} ; \text { deserto } \\
\text { ou semideserto frio. }\end{array}$ & $\mathrm{B}$ \\
\hline
\end{tabular}

Fonte: Köppen (1948).

Com os valores de temperatura, foi possível a obtenção do balanço hídrico climatológico, realizado a partir do método proposto por Thornthwaite e Mather (1955), com o auxílio do programa "BHnorm" elaborado em planilha eletrônica por Rolim, Sentelhas e Barbieri (1998), e tendo como parâmetro o CAD (capacidade de água disponível) de $100 \mathrm{~mm}$, que permitiu a obtenção dos valores normais da evapotranspiração potencial, excedente e deficiência hídrica, elementos que compõem o sistema classificatório de Thornthwaite (1948).

O método desenvolvido por Thornthwaite (1948) tem seus principais valores climáticos estabelecidos por: índice de umidade efetiva (Iue), eficiência termal anual, índice de aridez (Ia) e a concentração da eficiência termal do verão. O índice de umidade (Im) (Equação 1), que é o ponto de partida para o índice de umidade efetiva, é resultante dos valores de excedente hídrico dividido 
pela evapotranspiração potencial anual multiplicada por 100. O índice de umidade efetiva (Equação 2), que representa a primeira chave da classificação, é determinado pela relação entre o índice de umidade e o índice de aridez (Equação 3). A segunda chave da classificação é a eficiência termal, que é mensurada pela evapotranspiração potencial anual (Quadro 5).

$$
\mathrm{Iu}=\left(\frac{\mathrm{EXC}}{\mathrm{ETP}}\right) * 100(1) \quad \mathrm{Ieu}=\left(\frac{\mathrm{Iu}}{\mathrm{Ia} * 0,6}\right)
$$

Quadro 5 - Primeira chave, conforme os intervalos do índice de umidade (Ieu), e segunda chave, conforme o índice térmico (It), da tipologia climática de Thornthwaite (1948).

\begin{tabular}{c|c|c|c}
\hline $\begin{array}{c}\text { Tipo climático } \\
\text { (Primeira chave) }\end{array}$ & Índice de umidade $(\mathrm{Iu})$ & $\begin{array}{c}\text { Tipo climático } \\
\text { (Segunda chave) }\end{array}$ & $\begin{array}{c}\text { Índice térmico (It) } \\
\text { (Evapotranspiração potencial anual) }\end{array}$ \\
\hline $\mathrm{A}-$ Super-úmido & $100 \leq \mathrm{Iu}$ & $\mathrm{A}^{\prime}-$ Megatérmico & $\geq 1140$ \\
\hline $\mathrm{B}_{4}-$ Úmido & $80 \leq \mathrm{Iu}<100$ & $\mathrm{~B}^{\prime}{ }_{4}-$ Mesotérmico & $997-1140$ \\
\hline $\mathrm{B}_{3}-$ Úmido & $60 \leq \mathrm{Iu}<80$ & $\mathrm{~B}^{\prime}{ }_{3}-$ Mesotérmico & $855-997$ \\
\hline $\mathrm{B}_{2}-$ Úmido & $40 \leq \mathrm{Iu}<60$ & $\mathrm{~B}^{\prime}{ }_{2}-$ Mesotérmico & $712-855$ \\
\hline $\mathrm{B}_{1}-$ Úmido & $20 \leq \mathrm{Iu}<40$ & $\mathrm{~B}^{\prime}{ }_{1}-$ Mesotérmico & $570-712$ \\
\hline $\mathrm{C}_{2}-$ Sub-úmido & $0 \leq \leq \mathrm{lu}<20$ & $\mathrm{C}^{\prime}{ }_{2}-$ Microtérmico & $427-570$ \\
\hline $\mathrm{C}_{1}-$ Sub-úmido & $-33,3 \leq \mathrm{Iu}<0$ & $\mathrm{C}^{\prime}{ }_{1}-$ Microtérmico & $285-427$ \\
\hline $\mathrm{D}-$ Semi-árido & $66,7 \leq \mathrm{Iu}<-33,3$ & D' - Tundra & $142-285$ \\
\hline E - Árido & $-100 \leq \mathrm{Iu}<66,7$ & E' - Gelo perpétuo & $<142$ \\
\hline
\end{tabular}

Fonte: Thornthwaite (1948).

A primeira sub-chave de classificação climática é atribuída pelo índice de aridez, obtido pela relação entre os totais anuais de deficiência da água e da evapotranspiração potencial (Equação 3) para climas úmidos, e pelo índice de umidade (Equação 1) para climas secos (Quadro 6). A segunda sub-chave (CETv) é determinada pela proporção de evapotranspiração potencial concentrada no verão (Quadro 7).

$$
\mathrm{Ia}=\left(\frac{\mathrm{DEF}}{\mathrm{ETP}}\right) * 100
$$

Quadro 6 - Primeira sub-chave, conforme os intervalos do índice de aridez (Ia) para climas úmidos e do índice de

\begin{tabular}{|c|c|c|c|}
\hline $\begin{array}{c}\text { Tipo climático } \\
\text { (Primeira sub-chave) } \\
\text { Climas úmidos } \\
\left(\mathbf{A}, \mathbf{B}_{\mathbf{4}}, \mathbf{B}_{3}, \mathbf{B}_{2}, \mathbf{B}_{1}, \mathbf{C}_{2}\right)\end{array}$ & $\begin{array}{l}\text { Índice de } \\
\text { aridez (Ia) }\end{array}$ & $\begin{array}{c}\text { Tipo climático } \\
\text { (Primeira sub-chave) } \\
\text { Climas secos }\left(C_{1}, \text { D e E) }\right.\end{array}$ & $\begin{array}{c}\text { Índice de } \\
\text { umidade (Iu) }\end{array}$ \\
\hline $\mathrm{r}$ - pequena ou nenhuma deficiência hídrica & $0-16,7$ & $\begin{array}{c}\mathrm{D} \text { - pequena ou nenhum excesso } \\
\text { hídrico }\end{array}$ & $0-10,0$ \\
\hline $\mathrm{s}$ - moderada deficiência hídrica no verão & $16,7-33,3$ & $\begin{array}{c}\mathrm{s}-\text { moderado excesso hídrico no } \\
\text { inverno }\end{array}$ & $10,0-20,0$ \\
\hline w - moderada deficiência hídrica no inverno & $16,7-33,3$ & $\begin{array}{c}\text { w - moderado excesso hídrico no } \\
\text { verão }\end{array}$ & $10,0-20,0$ \\
\hline $\mathrm{s}_{2}-$ grande deficiência hídrica no verão & $>33,3$ & $\begin{array}{l}\mathrm{s}_{2}-\text { grande excesso } \\
\text { hídrico no inverno }\end{array}$ & $>33,3$ \\
\hline $\mathrm{w}_{2}-$ grande deficiência hídrica no inverno & $>33,3$ & $\begin{array}{l}\mathrm{w}_{2}-\text { grande excesso } \\
\text { hídrico no verão }\end{array}$ & $>20,0$ \\
\hline
\end{tabular}
umidade para climas secos, da tipologia climática de Thornthwaite (1948).

Fonte: Thornthwaite (1948). 
Quadro 7 - Segunda sub-chave, conforme a concentração de evapotranspiração potencial no verão (\%), da tipologia climática de Thornthwaite (1948).

\begin{tabular}{|c|c|}
\hline Tipo climático (Segunda sub-chave) & Concentração de evapotranspiração potencial no verão (\%) \\
\hline $\mathrm{a}^{\prime}$ & $<48$ \\
\hline $\mathrm{b}_{4}$ & $48-51,9$ \\
\hline $\mathrm{b}_{3}$ & $51,9-56,3$ \\
\hline $\mathrm{b}_{2}$ & $56,3-61,6$ \\
\hline $\mathrm{b}_{1}$ & $61,6-68,0$ \\
\hline $\mathrm{c}^{\prime}{ }_{2}$ & $68,0-76,3$ \\
\hline $\mathrm{c}{ }_{1}$ & $76,3-88,0$ \\
\hline $\mathrm{d}$ & $>88,0$ \\
\hline
\end{tabular}

Fonte: Thornthwaite (1948).

O método de Nimer (1972) classifica o clima de forma quantitativa, utilizando-se da temperatura e precipitação, e qualitativamente, por considerar a quantidade de meses secos (distribuição da pluviosidade) e a circulação atmosférica. Este sistema classificatório é composto por três partes:

1. Delimitação em conformidade com a variedade térmica, na qual se utilizam as isotermas referentes às médias mensais do mês mais frio (Quadro 8).

2. Classificação quanto ao maior ou menor grau de umidade, considerando-se a existência ou não de estação seca ou de estação subseca (Quadro 9). Para a estação seca, classifica-se qualquer mês cujo total de precipitação em milímetros é igual ou inferior ao dobro da temperatura média em ${ }^{\circ} \mathrm{C}(\mathrm{P} \leq 2 \mathrm{~T})$. Para a determinação de subseca os dados devem cumprir dois requisitos básicos. Primeiro, os locais estudados não devem possuir sequer um mês seco. A localidade cumprindo a primeira exigência deve ainda, num segundo momento, apresentar os meses em que $\mathrm{P} \leq 3 \mathrm{~T}$, que são considerados subsecos.

3. Em virtude das dificuldades em se encontrar os verdadeiros limites destes climas, o terceiro componente do sistema classificatório busca o apoio no entendimento da circulação atmosférica, análise do regime da distribuição das chuvas e temperatura durante as estações, relacionando com suas fontes dinâmicas de origem.

Quadro 8 - Primeira chave da tipologia climática de Nimer (1972) conforme a variedade térmica.

\begin{tabular}{|c|c|}
\hline Tipologia & Temperatura média do mês mais frio \\
\hline Clima quente & Superior a $18^{\circ} \mathrm{C}$ \\
\hline Clima Subquente & Entre $15^{\circ} \mathrm{C} \mathrm{e} 18^{\circ} \mathrm{C}$ em pelo menos 1 mês \\
\hline Clima mesotérmico brando & Entre $10^{\circ} \mathrm{C}$ e $15^{\circ} \mathrm{C}$ em pelo menos 1 mês \\
\hline Clima mesotérmico médio & Inferior a $10^{\circ} \mathrm{C}$ \\
\hline
\end{tabular}

Fonte: Nimer (1972).

A técnica de agrupamento foi empregada para a identificação de anos anômalos quanto à pluviosidade para a escala anual com a finalidade de escolher dois anos excepcionais, para o emprego e a análise comparativa dos sistemas de classificação climática considerados mais representativos para avaliar a variação do regime pluviométrico e a implicação de tal para a obtenção das tipologias climáticas. 
Quadro 9 - Segunda chave da tipologia climática de Nimer (1972) conforme o grau de umidade.

\begin{tabular}{|c|c|}
\hline Tipologia & Regime de chuvas \\
\hline Clima superúmido & Sem seca \\
\hline Clima Superúmido & Com subseca \\
\hline Clima úmido & Com 1 a 2 meses secos \\
\hline Clima úmido & Com 3 meses secos \\
\hline Clima semiúmido & Com 4 a 5 meses secos \\
\hline Clima semiárido branco & Com 6 meses secos \\
\hline Clima semiárido mediano & Com 7 a 8 meses secos \\
\hline Clima semiárido forte & Com a 10 meses secos \\
\hline Clima semiárido forte & Com 12 meses secos ses \\
\hline Clima desértico & \\
\hline
\end{tabular}

Fonte: Nimer (1972).

Para a realização do agrupamento, foi escolhida a distância Euclidiana, por mostrar-se adequado às características da variável em consideração. Adotou-se o método de ligação hierárquico Ward, que tem a atribuição de um elemento a um grupo feito de modo a minimizar a soma dos quadrados dentro dos grupos (MARTIN et al., 2008). Foi utilizado o software Statistica versão $7.0^{1}$ para o processo de análise cluster e para a sua representação gráfica a partir da elaboração do gráfico denominando dendograma, ou árvore de ligação, o qual apresenta um resumo do método aplicado.

Para a elaboração das cartas de classificação climática utilizou-se o aplicativo Surfer ${ }^{2}$, versão 7.0, que utiliza um arquivo com o contorno da área de estudo digitalizado, baseando-se nos valores de longitude e latitude, e outro arquivo com os valores delimitados para cada tipologia climática e os limites de suas respectivas coordenadas geográficas.

\section{RESULTADOS E DISCUSSÕES}

O emprego do sistema de classificação climática de Köppen (1948) indicou que os setores de maiores altitudes, localizados nas porções oeste e central da bacia hidrográfica, obtiveram a tipologia $\mathrm{Cfb}$ (subtropical mesotérmico úmido), de temperatura do mês mais frio inferior a $18{ }^{\circ} \mathrm{C} \mathrm{e}$ temperatura do mês mais quente inferior a $22{ }^{\circ} \mathrm{C}$, com ocorrência de pluviosidade em todos os meses do ano e inexistência de estação seca definida. O setor norte da bacia hidrográfica, com as mais elevadas temperaturas, obteve a tipologia climática $\mathrm{Cfa}$, que caracteriza um clima subtropical quente úmido, de temperatura do mês mais frio inferior a $18^{\circ} \mathrm{C}$ e temperatura do mês mais quente superior a $22{ }^{\circ} \mathrm{C}$, com ocorrência de pluviosidade em todos os meses do ano e inexistência de estação seca definida. Observa-se um setor ao sudeste e outro ao centro, que foram considerados como de transição entre as tipologias climáticas $\mathrm{Cfa}$ e $\mathrm{Cfb}$, entre as isotermas de $18,0{ }^{\circ} \mathrm{C}$ e $19,0{ }^{\circ} \mathrm{C}$, com o objetivo de evitar maiores generalizações (Figura 3A).

\footnotetext{
${ }^{1}$ Statistica é um produto registrado pela empresa StatSoft.

${ }^{2}$ Surfer é um produto registrado da empresa Golden Software Inc.
} 
Destaca-se que a distribuição espacial dos resultados do emprego da metodologia de classificação climática de Köppen (1948) para a área de estudo está aproximada ao obtido por Mendonça e Danni-Oliveira (2002) para a bacia hidrográfica do rio Tibagi, uma vez que indicaram a predominância da tipologia Cfb para o setor sul e Cfa para o setor norte, e uma porção situada no setor central como uma área de transição entre os dois tipos climáticos. Ainda, destaca-se que a obtenção da tipologia Cfa para o setor norte e sudeste, nos quais estão as menores elevações do relevo e as maiores médias térmicas, e $\mathrm{Cfb}$ para as porções de maiores altimetria e menores temperaturas médias, nos setores oeste e central, estão concordantes com os resultados obtidos por Alvares et. (2013) para este recorte do território brasileiro.

O sistema de classificação climática de Thornthwaite (1948) distingue a bacia hidrográfica do rio Itararé (PR) em seis setores de diferentes tipologias climáticas (Figura 3B). O setor oeste obteve a tipologia $\mathrm{B}_{4} \mathrm{r}{ }^{\prime}{ }_{2}$ a', que designa um clima úmido mesotérmico, de pequena ou nenhuma deficiência térmica e concentração de evapotranspiração potencial no verão inferior a 48\%, representando que esta porção da bacia hidrográfica apresenta os maiores índices de umidade e as menores eficiências térmicas. O setor sudeste caracteriza-se pela tipologia $\mathrm{B}_{4} \mathrm{r} \mathrm{B}_{3} \mathrm{a}^{\prime}$, com os mesmos níveis do índice de umidade que o setor sudeste, mas que apresenta uma maior eficiência térmica, resultante de maiores médias térmicas. Os setores sul e sudoeste obtiveram a tipologia climática $\mathrm{B}_{3} \mathrm{r}^{\mathrm{B}}{ }_{2}{ }_{2} \mathrm{a}^{\prime}$, que demonstra um clima úmido mesotérmico, de pouca ou nenhuma deficiência hídrica e concentração de evapotranspiração potencial no verão inferior a $48 \%$, de menores valores do índice de umidade em relação aos setores oeste e sudeste e com características de menores eficiências térmicas. Com uma maior eficiência térmica em relação aos setores sul e sudoeste, os setores leste e central da bacia hidrográfica receberam a tipologia $\mathrm{B}_{3} \mathrm{r} \mathrm{B}_{3}{ }_{3}$ a', que descreve um clima mesotérmico úmido de pouca deficiência hídrica e concentração de evapotranspiração potencial no verão inferior a $48 \%$.

Com características de maiores médias térmicas e menores alturas pluviométricas, verificouse para o setor norte da bacia hidrográfica a tipologia climática $\mathrm{B}_{2} \mathrm{r} \mathrm{B}_{3}{ }_{3}$ ', que representa um clima mesotérmico úmido de pouca deficiência hídrica e concentração de evapotranspiração potencial no verão inferior a $48 \%$ e índices de umidade efetiva inferior aos verificados em setores meridionais. $\mathrm{O}$ setor noroeste da bacia hidrográfica, com os menores índices de umidade e as maiores eficiências térmicas, caracteriza-se pela tipologia $\mathrm{B}_{1} \mathrm{r} \mathrm{B}_{4} \mathrm{a}$, de clima úmido mesotérmico, pouca ou nenhuma deficiência hídrica e concentração de evapotranspiração potencial no verão inferior a $48 \%$.

Os resultados da utilização do sistema de classificação climática de Thornthwaite (1948) estão aproximados aos obtidos por Jurca (2005) para este recorte da região sul do Brasil, com maiores índices de umidade efetiva para os setores meridionais, com uma tendência a redução desse índice para os setores setentrionais. 


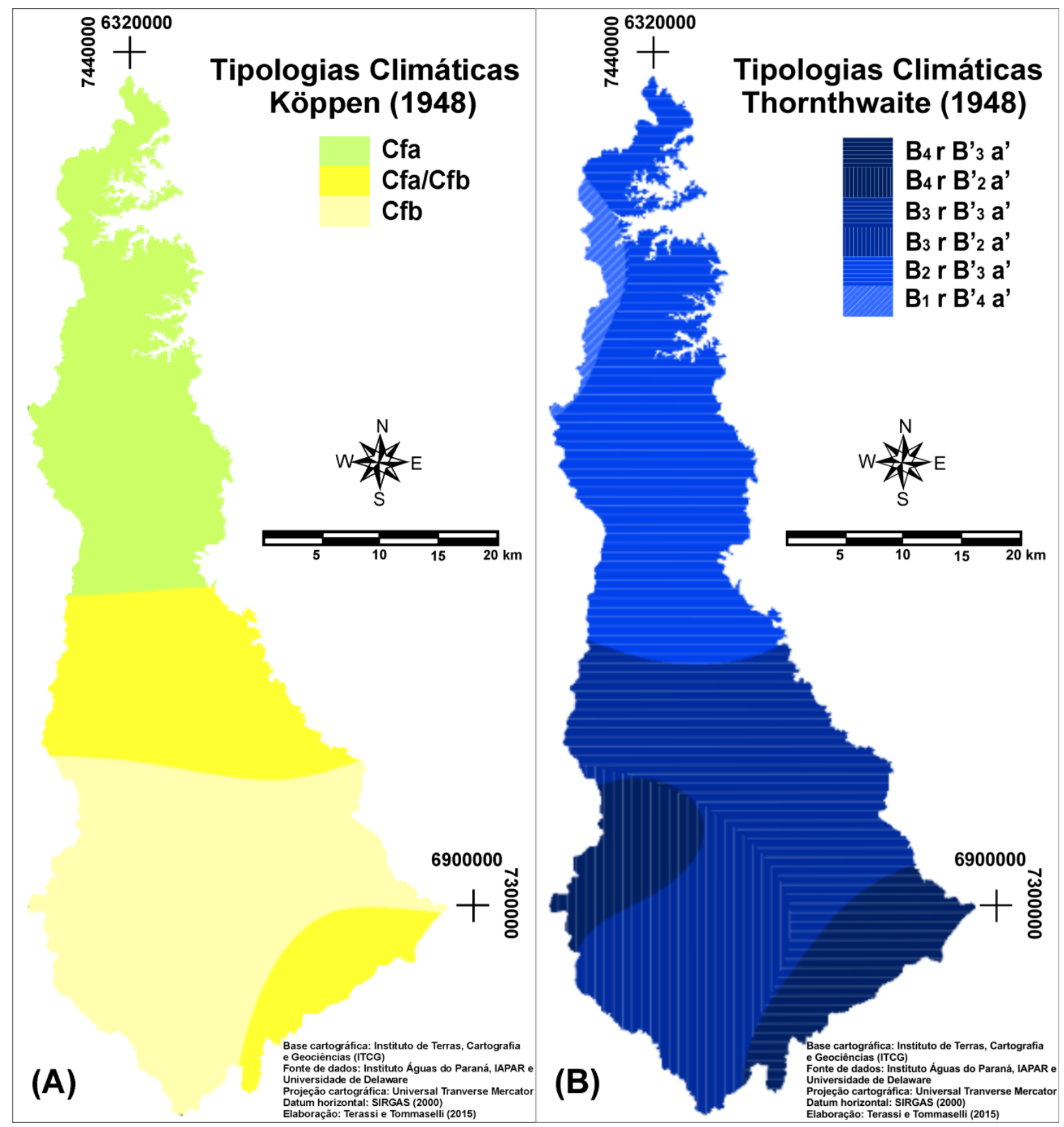

Figura 3 - Distribuição espacial das tipologias climáticas de Köppen (1948) (A) e Thornthwaite (1948) (B) para a bacia hidrográfica do rio Itararé - PR.

O método classificatório de Nimer (1972) estabeleceu três tipologias climáticas para a bacia hidrográfica do rio Itararé. Os setores oeste e central obtiveram a tipologia mesotérmico brando superúmido sem subseca e com a atuação mais incisiva de sistemas atmosféricos extratropicais, caracterizando-se por médias térmicas inferiores a $15^{\circ} \mathrm{C}$ no mês mais frio e regularidade do regime pluviométrico, condição atribuída pelo fator orográfico, latitudinal e a circulação atmosférica tipicamente inerente à região Sul do Brasil. O setor norte foi classificado como de clima subquente úmido com subseca em agosto e de atuação incisiva de sistemas atmosféricos intertropicais, por apresentar, conforme Nimer (1989), uma dinâmica atmosférica aproximada a do Brasil Central, com uma redução significativa da pluviosidade para os meses de inverno e maiores médias térmicas em relação aos demais setores da bacia hidrográfica. Com características de maior regularidade das 
chuvas em relação ao setor norte e maiores médias térmicas em comparação ao setor oeste e central, as demais porções da bacia hidrográfica foi denominada de subquente superúmido sem subseca com circulação atmosférica transitória (Figura 4).

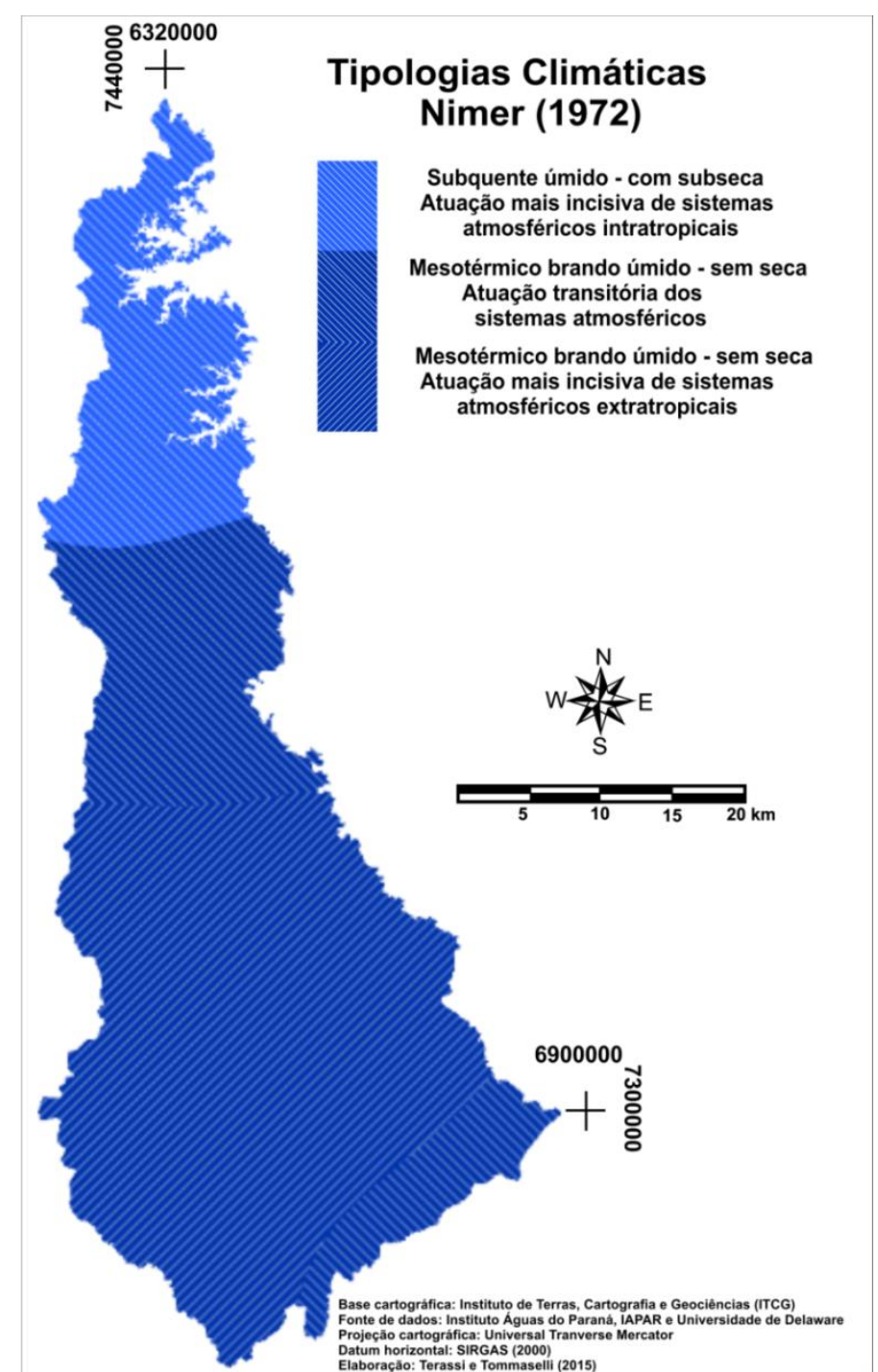

Figura 4 - Distribuição da tipologia climática de Nimer (1972) para a vertente paranaense da bacia hidrográfica do rio Itararé.

O sistema classificatório de Köppen (1948) mostrou-se bastante associado à distribuição espacial das isotermas anuais e, sobretudo, com as Formações Fitogeográficas, uma vez que os Campos Naturais e a Floresta Ombrófila Mista Altomontana, localizados nos setores oeste e central, obteve-se a tipologia Cfb, enquanto para a Floresta Estacional Semidecidual, no setor norte da bacia hidrográfica, verificou-se a tipologia Cfa. Essa constatação quanto aos resultados obtidos pela classificação climática de Köppen (1948) se explica pelo fato de que para estabelecer seus limites climáticos este autor baseou-se a partir do reconhecimento dos grandes grupos vegetacionais.

Contrariamente, Thornthwaite (1948) iniciou o estabelecimento dos intervalos das tipologias climáticas conforme a eficiência térmica e os índices de umidade e, posteriormente, modificou os 
limites com base na distribuição da vegetação. Principalmente, o sistema de classificação climática de Thornthwaite (1948) possibilitou distinguir com eficácia as características climáticas do recorte de estudo, fornecendo de forma conjunta às informações provenientes do balanço hídrico climatológico, sendo uma ferramenta útil para a determinação de zonas agroclimáticas e para o gerenciamento dos recursos hídricos.

Ainda com relação ao regime pluviométrico, enquanto que o sistema classificatório de Köppen (1948) identificou somente a tipologia " $\mathrm{f}$ " indicando ausência de estação seca e regularidade pluviométrica, o método de Nimer (1972) indicou que o setor setentrional da bacia hidrográfica apresenta características de subseca para o mês de agosto. Embora o regime pluviométrico esteja indissociável das características térmicas, o método de Thornthwaite (1948) não identificou riscos a seca ou subseca, apresentando somente a tipologia " $r$ ", que indica pouca ou nenhuma deficiência hídrica. Dessa forma, indica-se que o método classificatório de Nimer (1972) tem seus méritos na tentativa de separação dos climas a partir do conjunto de características dos elementos climáticos e da circulação atmosférica, além de possibilitar identificação dos setores mais suscetíveis a eventos de subseca.

Com o intuito de averiguar a capacidade de mensurar e avaliar o regime hídrico, para além das normais climatológicas, foram utilizados os sistemas de classificação climática de Thornthwaite (1948) e Nimer (1972) para avaliar a variação dos limites climáticos em anos excepcionais quanto ao volume de pluviosidade. A identificação dos anos excepcionais quanto aos totais anuais de pluviosidade, realizada a partir do agrupamento demonstrado pela figura 5, permitiu descriminar os anos de 1983, caracterizado como chuvoso, e 1985, denominado de seco. Esses anos foram caracterizados pela predominante ocorrência dos fenômenos El Niño e La Niña, respectivamente. O evento de El Niño do ano de 1983, ocorrido também em 1982, foi determinante para o aumento superior a $600 \mathrm{~mm}$ para o setor sul e a $200 \mathrm{~mm}$ para o setor norte da área de estudo, conforme aponta Sousa (2006). Esta mesma autora destaca que o ano de 1985 apresentou uma redução pluviométrica superior a $400 \mathrm{~mm}$ para a porção na qual está situada a bacia hidrográfica do rio Itararé (PR).

A partir da seleção da metodologia de Thornthwaite (1948) como a mais adequada para atender às exigências do zoneamento agroclimático à gestão de recursos hídricos, verificou-se a necessidade da aplicação dos parâmetros delimitados por esse sistema de classificação climática para os anos de comportamento adverso da pluviometria. Comparativamente, estão dispostos os resultados para os referidos anos na figura 6, com o intuito de ressaltar que a utilização da série histórica não possibilita a verificação das principais oscilações do regime hídrico. 


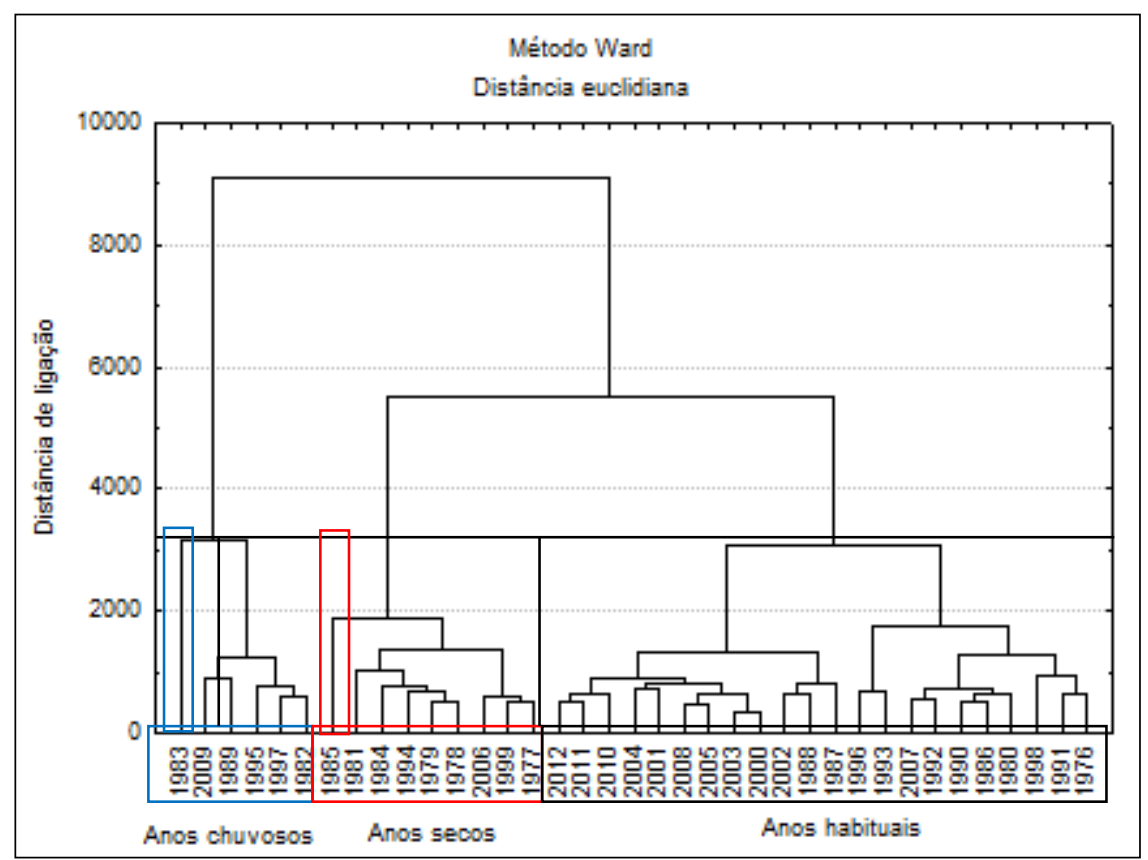

Figura 5 - Dendograma do agrupamento em anos chuvosos, secos e habituais para a pluviosidade anual $(\mathrm{mm})$ na bacia hidrográfica do rio Itararé - PR.

$\mathrm{O}$ ano com a maior média anual de pluviosidade para toda a bacia hidrográfica, equivalente a $2080 \mathrm{~mm}$, apresentou uma relativa homogeneidade quanto às tipologias obtidas. Os setores sul, central e leste da bacia hidrográfica apresentaram os maiores valores de excedente hídrico e do índice de umidade efetiva, com a predominância da tipologia A para a primeira chave desse sistema classificatório. O setor norte da área de estudo apresentou uma menor interferência do aumento de pluviometria e, junto a sua característica habitual de maiores temperaturas, registrou os menores índices de umidade efetiva, o que lhe atribui as tipologias $\mathrm{B}_{4}$ e $\mathrm{B}_{3}$ para a primeira chave classificatória. Os demais componentes do método de Thornthwaite (1948) registraram para o ano de 1983 as mesmas condições em relação aos resultados para a série histórica: pouca ou nenhuma deficiência hídrica; concentração de evapotranspiração inferior a 48\% nos meses de verão; maiores valores de eficiência térmica para o setor setentrional, com uma redução nas porções ao sul (Figura 6).

Com a redução significativa da pluviometria, com uma média de 930,5 mm, o ano de 1985 se caracterizou pela elevada redução dos valores de excedente hídrico, com a redução dos níveis de umidade efetiva. Esse cenário permitiu identificar a tipologia $C_{1}$ (sub-úmido seco) para o setor leste da bacia hidrográfica, onde foram identificados valores de pluviosidade inferiores a $750 \mathrm{~mm}$ anuais, sendo que essa condição permite estabelecer que a região mencionada apresentasse a maior probabilidade às deficiências hídricas. Observa-se que grande parte da bacia hidrográfica obteve a tipologia $C_{2}$ (sub-úmido), enquanto que o setor sudeste apresentou a classificação $B_{1}$, indicando que esse último setor é o que apresenta os menores riscos de ocorrência de deficiência hídrica. Os demais componentes classificatórios não apresentaram diferenças em relação ao identificado para a 
série histórica (1976-2012) e para o ano excepcional chuvoso. Essa última consideração revela que, embora tenham sido verificadas deficiências hídricas, sobretudo pela obtenção das tipologias $\mathrm{C}_{1} \mathrm{e}$ $\mathrm{C}_{2}$, os valores foram pouco relevantes para a alteração da chave secundária do sistema classificatório (Figura 6).

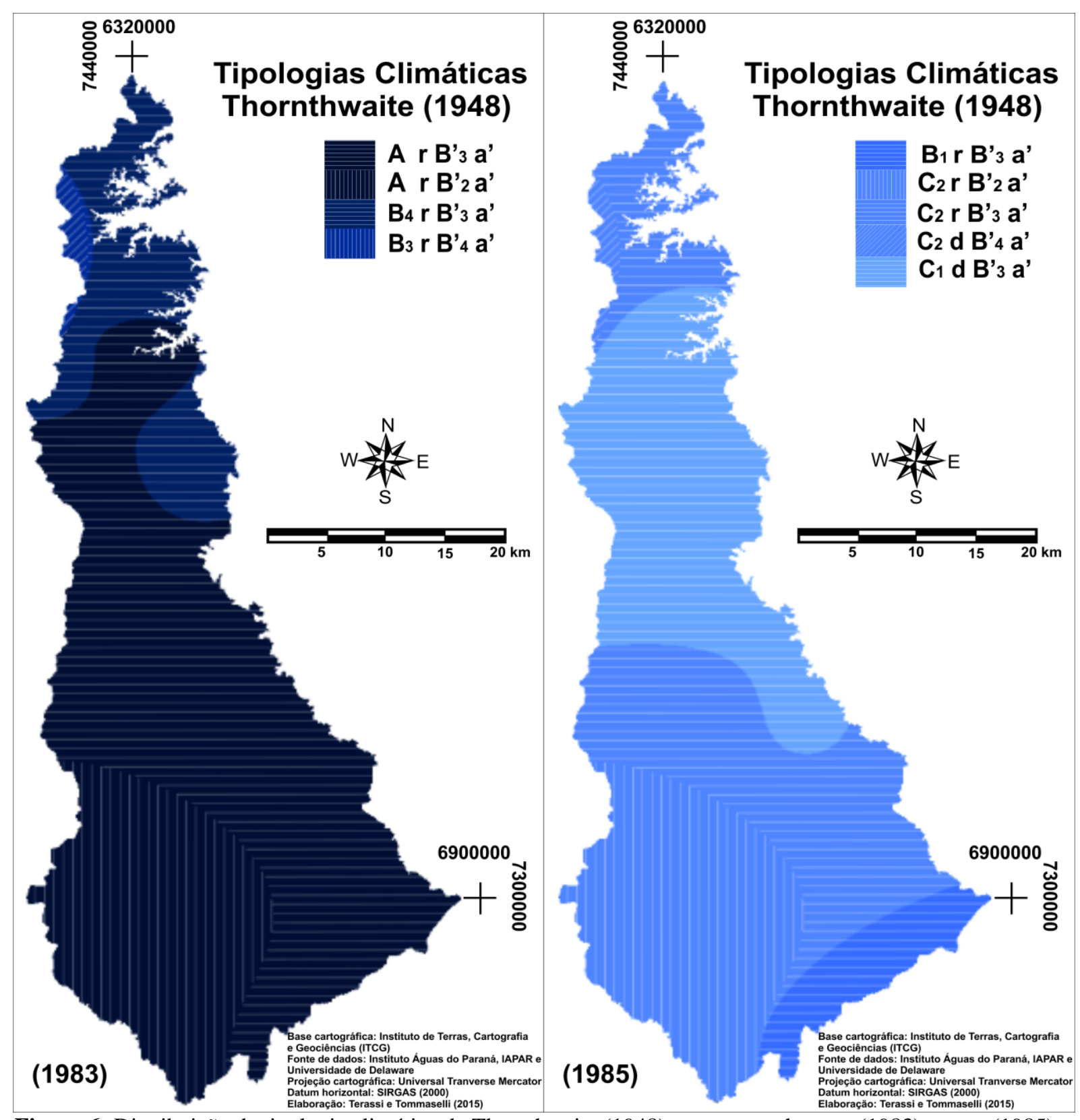

Figura 6- Distribuição da tipologia climática de Thornthwaite (1948) para o ano chuvoso (1983) e seco (1985) para a bacia hidrográfica do rio Itararé - PR.

A aplicação do sistema classificatório de Nimer (1972) em anos excepcionais para a porção paranaense da bacia hidrográfica do rio Itararé identificou as peculiaridades do impacto do regime pluvial, conforme demonstra a Figura 7. Essas características foram destacadas pela variação do regime termo-pluviométricas em relação às tipologias identificadas para a série histórica, o que 
demonstra com clareza à demasiada generalização da utilização univalente e limitada das normais climatológicas.

Avalia-se que o ano chuvoso de 1983, mesmo com registros de pluviosidade maiores que o habitual, apresentou a tipologia úmida com a verificação de seca para um ou dois meses para todos os setores da bacia hidrográfica. Quanto ao regime térmico, observa-se uma redução da abrangência da tipologia subquente, indicando a redução da média térmica do mês mais frio para a região de estudo e, consequentemente, uma maior porção denominada de mesotérmica. Conclui-se, por conseguinte, que até mesmo em condições de elevadas pluviosidades anuais, a região de estudo pode apresentar, eventualmente, períodos de deficiência hídrica.

Com uma maior diversidade de tipologias identificadas, o ano seco de 1985 demonstrou que, excepcionalmente, a porção norte da bacia hidrográfica do rio Itararé (PR) pode estar condicionada a situações atmosféricas de seca típica do clima semi-árido do Nordeste brasileiro, salva pela significativa redução térmica desta área de estudo. Indicou-se, da mesma forma que observada para o ano excepcional chuvoso, um aumento das porções definidas como mesotérmicas, mostrando uma redução do potencial térmico para o ano excepcional mencionado.

Nas proximidades da represa de Chavantes, o setor norte caracterizou-se no ano de 1985 pela tipologia subquente semi-árido com seca de 6 meses. Ainda, em boa parte do setor norte da bacia hidrográfica, verificou-se a obtenção da tipologia Subquente e Mesotérmico, essa última para a porção de média térmica do mês mais frio inferior a $15,0^{\circ} \mathrm{C}$, com o caráter semi-úmido e com o registro de 4 a 5 meses de seca. Em parte das porções central e sudeste observa-se a tipologia mesotérmico semi-úmido com seca de 3 meses. Os setores oeste, sul e central receberam a tipologia mesotérmico úmido com 1 a 2 meses de seca, configurando essas porções como a de menor probabilidade de ocorrência de eventos de estiagens prolongadas ou secas.

O sistema classificatório de Nimer (1972) não permitiu, à vista disso, identificar as implicações do aumento de pluviosidade para o ano chuvoso de 1983, mas mostrou que, mesmo no ano mais chuvoso da série histórica, existe a possibilidade de ocorrência de seca em 1 a 2 meses na bacia hidrográfica do rio Itararé (PR). O sistema classificatório de Thornthwaite (1948) mostrou a variação espacial do aumento de pluviosidade a partir da espacialização do índice de umidade efetiva e demonstrou que os setores meridionais da bacia hidrográfica são àqueles de maior aumento do potencial hídrico. Ao passo que o método de Thornthwaite (1948) não identificou variações do potencial térmico em relação à normal climatológica, o método de Nimer (1972) mostrou uma pequena redução para o setor norte da área de estudo.

Enquanto que o sistema de classificação climática de Thornthwaite (1948) demonstrou que o setor leste é o que demonstra a maior propensão à deficiência hídrica $\left(\mathrm{C}_{2}\right)$ para o ano seco, o método de Nimer (1972) delimitou o setor norte como o de maior ocorrência de meses secos para o 
ano de 1985. Dessa informação, analisa-se que os setores leste e norte compreendem as áreas que, seja quantitativamente ou qualitativamente, as que apresentam os maiores riscos de estiagens. Comparativamente, o último sistema classificatório mencionado permitiu averiguar com mais eficiência a variação do regime térmico dos anos excepcionais em relação à normal climatológica.

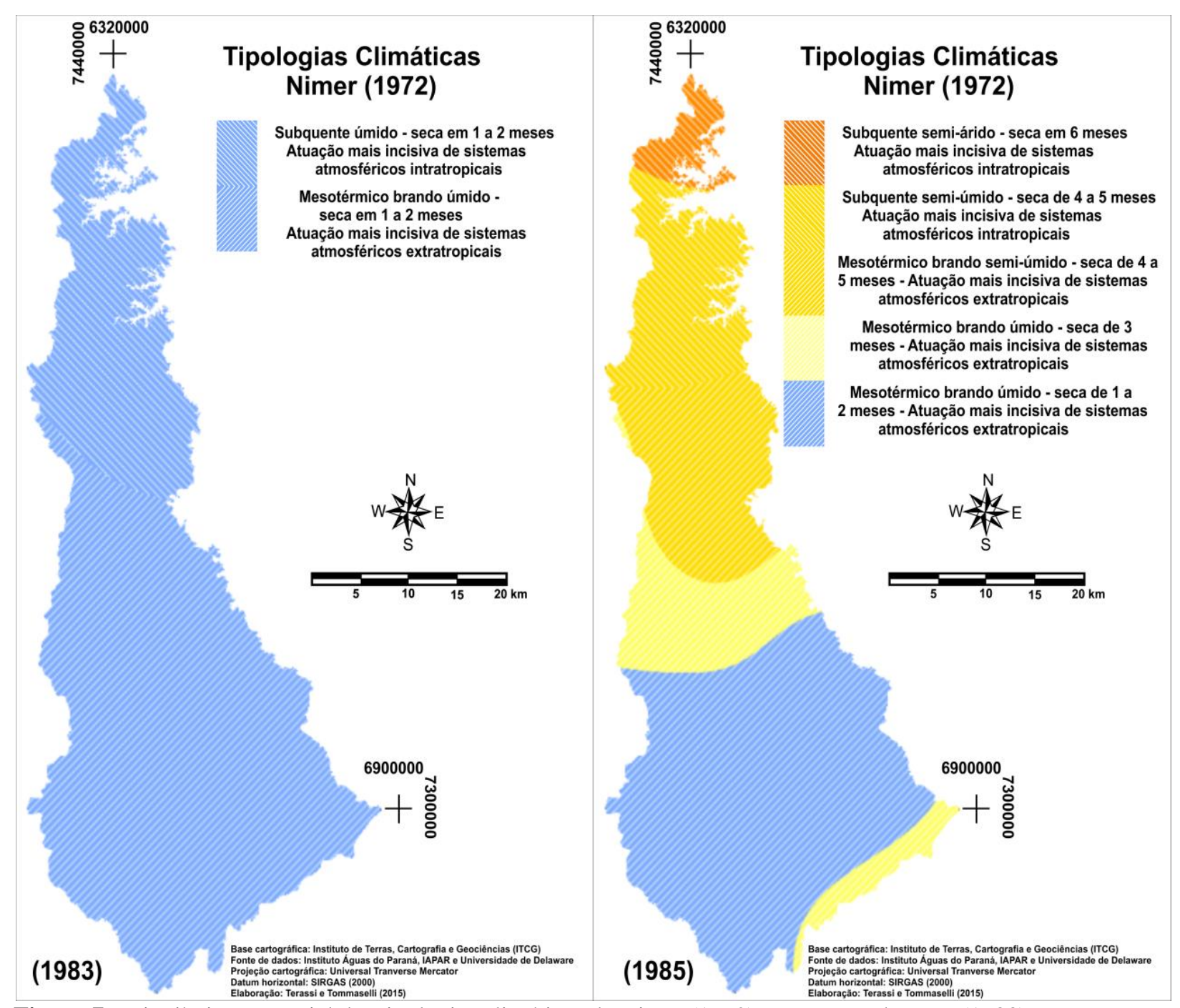

Figura 7 - Distribuição espacial das tipologias climáticas de Nimer (1972) para o ano chuvoso (1983) e o ano seco (1985) na bacia hidrográfica do rio Itararé - PR.

\section{CONSIDERAÇÕES FINAIS}

Com diferentes critérios, mostrou-se que a metodologia de Köppen (1948) tem uma associação mais adequada com a distribuição das isotermas e com as formações fitogeográficas originais, enquanto o emprego da metodologia de Thornthwaite (1948) mostrou-se mais efetivo por distinguir os tipos climáticos como subsídio específico para o zoneamento agroclimático e gerenciamento de recursos hídricos. Por sua vez, a classificação climática de Nimer (1972) determinou as características do clima de determinada região a partir de um conjunto de fatores 
climáticos, sobretudo a circulação atmosférica, e os elementos climáticos pluviosidade e temperatura.

A identificação dos anos excepcionais possibilitou discutir a variação dos atributos climáticos de forma qualitativa em relação às normais climatológicas, demonstrando as restrições do uso de séries históricas para a compreensão do clima da região. Por esse motivo, foram selecionados dois anos representativamente excepcionais pela pluviometria anual para o emprego das duas técnicas de classificação climática avaliadas como mais adequadas para mensurar as características do regime hídrico, a de Thornthwaite (1948) e Nimer (1972).

Dentre as análises mais importantes, destaca-se a verificação de tipologias que apontam clima semi-árido para as porções norte e leste da bacia hidrográfica para o ano seco (1985). Esses setores foram os que apresentaram a maior redução do volume de pluviosidade durante o ano de 1985, no qual se verificou a atuação do La Niña. Destacando o caráter de distorção das normais climatológicas, o ano excepcional chuvoso (1983), de ocorrência do El Niño, indicou para a classificação de Nimer (1972) um clima úmido, mas com 1 a 2 meses de seca para toda a bacia hidrográfica, ao passo que o sistema classificatório de Thornthwaite (1948) apenas descreveu o elevado acréscimo de pluviosidade.

\section{REFERÊNCIAS}

ÁlvareS, C. A.; STAPE, J. L.; SENTELHAS, P. C.; DE MORAES GONÇALVES, J.L.; SPAROVEK, G. Köppen's climate classification map for Brazil. Meteorologische Zeitschrift, Berlin, v. 22, n.6, p. 711-728, 2013.

ITCG (Instituto de Terras, Cartografia e Geodésia). Produtos Cartográficos. Disponível em: <http://www.itcg.pr.gov.br/modules/conteudo/conteudo. php?conteudo=47. Acesso em 14 de julho de 2014.

JURCA, J. Classificações Climáticas: variações têmporo-espaciais e suas aplicações nos livros didáticos e como subsídio ao zoneamento agroclimático. 2005. 150f. Dissertação (Mestrado). Programa de Pós-Graduação em Geografia, Universidade Estadual Paulista "Júlio de Mesquita Filho", Presidente Prudente, 2005.

KÖPPEN, W. Climatologia: con un estudio de los climas de la tierra. Fondo de Cultura Econômica. México. 1948. 479p.

MAACK, R. Geografia Física do estado do Paraná. 4a Edição. Ponta Grossa: Editora UEPG. 2012. 526p.

MARTIN, T. N.; NETO, D. D.; VIEIRA JUNIOR, P. A.; MANFRON, P. A. Homogeneidade espaço temporal e modelos de distribuição para a precipitação pluvial no estado de São Paulo. Revista Ceres, Viçosa, v.55, n.5, p. 476-481, 2008. 
MENDONCA, F. A.; DANNI-OLIVEIRA, I. M. Dinâmica atmosférica e tipos climáticos predominantes na bacia do rio Tibagi. In: MEDRI, M.; BIANCHINI, E.; SHIBATTA, O. A.; PIMENTA, J. O. (Org.). A bacia do Rio Tibagi. Londrina: Moacir E. Medri Editores, v. 1, p. 6368. 2002.

MENDONÇA, F. A; DANNI-OLIVEIRA, I. M. Clima: Noções básicas e climas do Brasil. São Paulo: Editora Oficina de Textos, 2007.207p.

NIMER, E. Ensaio de um novo método de classificação climática: contribuição à climatologia intertropical e subtropical, especialmente do Brasil. Boletim de Geografia. Rio de Janeiro, v. 31, n.277, p.141-153, 1972.

NIMER. E. Climatologia do Brasil. $2^{\text {a }}$ Edição. Rio de Janeiro: Instituto Brasileiro de Geografia e Estatística, 1989. 421p.

NÓBREGA, R.S. Um pensamento crítico sobre classificações climáticas: de Köppen até Strahler. Revista Brasileira de Geografia Física, Recife, v.3, n.1, p.18-22, 2010.

OMETTO, J. C. Bioclimatologia vegetal. São Paulo, Ed. Agronômica Ceres, 1981, 425p.

PELL,M.C.; FINLAYSON, B.L.; MCMAHON, T.A. Update world map of the Köppen - Geiger climate classification. Hydrology and Earth System Sciences, Munich, v.11, n.1, p.1633-1644, 2007.

ROLIM, G. S.; SENTELHAS, P. C.; BARBIERI, V. Planilhas no ambiente EXCEL para os cálculos de balanços hídricos: normal, sequencial, de cultura e de produtividade real e potencial. Revista Brasileira de Agrometeorologia, Santa Maria, v.6, p.133-137, 1998.

ROLIM, G. S.; CAMARGO, M. B. P.; LANIA, D. G.; MORAES, J. F. L. Classificação climática de Köppen e de Thornthwaite e sua aplicabilidade na determinação de zonas agroclimáticas para o estado de São Paulo. Bragantia, Campinas, v. 66, n.4, p. 257-533, 2007.

SOUSA, P. Estudo da precipitação no estado do Paraná associada à anomalia TSM do Oceano Pacífico. 2006. 72f. Dissertação (Mestrado). Programa de Pós-Graduação em Geografia, Universidade Estadual de Maringá, Maringá, 2006.

THORNTHWAITE, C. W. An approach towards a rational classification of climate. Geographycal Review London, Nova Jersey n.38, p.55-94. 1948.

THORNTHWAITE, C. W.; MATHER, J.R. The water balance climatology. Centerion, v.8, n. 1, p.1-86.1955.

TUBELIS, A.; NASCIMENTO, F.J.L. Meteorologia descritiva: Fundamentos e aplicações brasileiras. São Paulo: Nobel, 1984. 372p.

UDEL (University of Delaware). Air temperature and precipitation. Disponível em: < http://www.esrl.noaa.gov/psd/data/gridded/data.UDel_AirT_Precip.html>. Acesso em 12 de maio de 2014.

VIANELLO, R. L.; ALVES, A. R. Meteorologia básica e aplicações. Viçosa: UFV, 1991, 449p. 
VILlELA, S. M.; MATTOS, A. Hidrologia aplicada. São Paulo: McGraw-Hill do Brasil, 1975. $245 p$.

Trabalho enviado em março de 2016 Trabalho aceito em julho de 2016 